Please refer to the definitive version of this article when citing:

Cohen, S.A. \& Gössling, S. (2015). A darker side of hypermobility. Environment and Planning A, 47, 1661-1679.

\title{
A darker side of hypermobility
}

Since the formulation of the mobilities paradigm, research has shown that movement is increasingly at the heart of our social identities. This paper argues that mobility, and indeed, hypermobility, constitutes to a growing extent who we are, while societal perspectives on mobility increasingly dictate how we need to move in time and space in order to accrue network capital. In this critical review, deeply embedded mechanisms of the social glamorization of mobility are uncovered, and juxtaposed with what we call a 'darker side' of hypermobility, including the physiological, psychological, emotional and social costs of mobility for individuals and societies. The paper concludes that while aspects of glamorization in regard to mobility are omnipresent in our lives, there exists an ominous silence with regard to its darker side.

Keywords: glamorization, network capital, mobility consequences, transport, behaviour change

\section{Introduction}

Elite forms of movement, such as for business, holidays or diplomatic journeys, are largely shown in a positive light in contemporary societies. Although there is unevenness in the portrayal of corporeal mobilities, with for instance growing fear over epidemiological threats facilitated through global mobility, negative representations of flight from poverty and persecution and the problematizing of irregular migration, mobility for business and pleasure 
is typically glamorized and encouraged in more privileged societies. The glamorization of elite mobility is part of broader processes of global capitalist consumption within conditions of neoliberalism, wherein circulation and accumulation within networks is unevenly experienced and materialized. Social capital is increasingly based on one's power to be mobile and cultivate global networks, or what Larsen, Axhausen and Urry (2006) refer to as 'network capital'. Network capital is understood here as interrelationships between social relations and social support (Carrasco and Cid-Aguayo, 2012); that is, as a form of social capital that makes “resources available through interpersonal ties" (Wellman and Frank 2001, page 273). As social networks become more dispersed, "access to communication technologies and affordable and well-connected transport", for instance, are elements comprising network capital, as they make ties in social networks more accessible (Larsen et al, 2006, page 280; Gössling and Stavrinidi 2015; Rettie 2008).

Both network capital and mobility are, however, not evenly distributed across societies (Cresswell, 2010). The life-chances it affords are 'heavily skewed' also (Urry, 2012), with a minor share of highly mobile individuals accounting for a major proportion of the overall distances travelled (Gössling et al., 2009). This mobile elite is well connected to global networks, and have been described as 'hypermobile', with these hypermobile lifestyles closely but not exclusively linked to the practice of business travel (Frändberg and Vilhelmson, 2003). For example, in Sweden, just $3 \%$ of the population undertake nearly a quarter of all international journeys (Frändberg and Vilhelmson, 2003), whereas in France 5\% of the population account for as much as $50 \%$ of the overall distances covered (Gössling et al, 2009).

The high social status associated with frequent corporeal mobility in some more privileged societies, specifically by air and road, is at least partly attributable to its glamorization in the media and other forms of public discourse (Thurlow and Jaworski, 2006). The purpose of this 
critical review is to further investigate the social mechanisms through which hypermobility is glamorized in the contemporary world. We define 'glamorization' as the social processes by which something is idealized and made desirable. Our aim is to show how network capital is constructed through mobility, and the manifold mechanisms through which transport and mobility have become signifiers of social status. By doing so, we reveal some of the fundamental social processes through which hypermobility is made exciting and appealing. We juxtapose this with an examination of the darker side of hypermobility, in terms of its physiological, psychological, emotional and social consequences for individuals and society. We argue that the glamorization of hypermobility has silenced the negative personal and social costs of frequent travel. This juxtaposition of the darker sides of hypermobility with the mechanisms of its glamorization is consequently a methodological inroad to make transparent the one-sided mirror that frames hypermobility as desirable. The geographical lens in this paper is largely Northern European, drawing on empirical examples, cases and literature on both business and leisure travel from different places within that region.

\section{Methodology}

Our methodological approach to the literature is that of a critical review (Grant and Booth, 2009). We offer a synthesis of studies of business and leisure travel, transport, and network capital, including a review of processes that glamorize mobility and, in juxtaposition, a discussion of the negative consequences of corporeal mobility, in order to provide a reinterpretation of frequent travel. Our approach follows others who "attempted to innovate outside the frame offered by conventional systematic review methodology", and have used 'organic, creative and interpretive approaches to conducting reviews of complex literature' (Dixon-Woods et al, 2006a, page 39). As the review does not offer the systematicity of a more structured approach, its interpretative synthesis is subjectively biased, is not comprehensive, and should be viewed as a starting point or 'launch pad' rather than an end in itself (Grant and 
Booth, 2009). The review is furthermore inflected by a desire to intervene in dominant discourses that represent hypermobility as glamorous; it is consequently conditioned by our values.

The most significant papers in this area, and further relevant papers, were identified iteratively using the former papers' reference lists. We furthermore drew on our own previous empirical work on frequent flying and mobile lifestyles. Peer-reviewed journal articles were included without further formal rules of quality assessment, and our synthesis is presented through a narrative discussion that is inherently reductive of others' arguments. A strength of this iterative approach is that unlike conventional, rationalist models of systematic reviews, it allows us to incorporate both qualitative and quantitative studies, draw on literature across the diffuse boundaries of overlapping fields, and prioritize papers based on relevancy (Dixon-Woods et al, 2006b). Such an approach gives leverage in exploring complex questions that reflect the “inherently contingent, intuitive and fuzzy realities of practice and experience" (Dixon-Woods et al, 2006a, page 30). By bringing ideas together in new ways, this synthesis of evidence opens up new possibilities for reinterpreting dominant representations of hypermobility.

\section{The Glamorization of Hypermobility}

There is general agreement that sections of some societies are increasingly mobile (cf Sheller \& Urry, 2006 on the mobility turn in the social sciences), and such contemporary forms of living and dwelling have been termed 'liquid modernity' (Bauman, 2007). Liquid modernity is characterised by social structures rapidly evolving and dissolving, and a near constant transformation of selves in a psychological situation of insecurity, anxiety and pleasureorientation. This process is, according to Bauman, fuelled by individualism in a globalized world shaped by global, hypermobile elites, who frequently change places of work, residence and social networks. Mobility thus permeates, albeit unevenly through power asymmetries, 
societies and collective psychologies, shaping individual and national identities founded in near constant movement (Adey, 2010; Edensor, 2004). Mobility is a prerequisite for work, leisure and relations, and increasingly defines one's standing in society, as well as one's 'network capital' (Urry, 2012).

Highly mobile lifestyles involve a socialization process, which frames how we understand and value mobility from early childhood (Frändberg, 2008; Lassen, 2006; Schwanen et al, 2012; Sheller, 2004). Specifically, it has been argued that contemporary societies assign high social value to the consumption of distance, to 'being mobile' (Riber Larsen and Guiver, 2013; Urry, 2007; 2012). Where mobility patterns turn into an object of admiration, they become a signifier of social status and thus a social necessity, shaping what might be termed 'liquid identities', which after Bauman (2007), are defined as social identities increasingly modelled and built on mobilities (Gössling and Stavrinidi, 2015). Liquid identities are interwoven with privileged access to resources, including technology use: smartphones are used to download maps and timetables, to navigate, book accommodation, rent cars or buy air tickets. Social media make mobile lives more visible to peers. Personalized cars reduce mental and corporeal insecurities and anxieties (Gössling, 2013), creating spaces of man-machine co-existence to which drivers become emotionally attached (Nilsson and Küller, 2000). Reward systems such as frequent flyer programs recompense mobility with more mobility (Gössling and Nilsson, 2010). These mobility patterns not only assign status and network capital to travel, but also engender considerable inequalities by assigning anti-status to the less mobile. Such uneven politics of mobility are both produced by social relations and are productive of them (Cresswell, 2010), as for example Adey (2006) observes in the context of airports, where individuals are divided into slow and fast-moving streams, performing 'kinetic elites' and 'kinetic underclasses'.

In this paper, it is argued that these processes are reinforced by ubiquitous patterns of 
glamorization of (hyper)mobility, involving a wide range of different mechanisms. Contemporary patterns of 'transport glamorization' -- i.e. processes of idealising behaviour or objects related to mobility -- have received scant attention in the literature. For instance, Grube (2005) concluded that the prevention of drunk driving was difficult because of the broad social glamorization of alcohol, while Barry (2007) investigated the glamorized femininity of flight attendants, for decades represented by young, attractive, unmarried, white women; see also Baum (2012), who traces representations of female flight attendants from the 1930s 'golden era'. Yet, the scattered nature of research into the glamorization of mobility indicates that limited attention has been given to glamorization processes. These are omnipresent, however, and are often more profound and subtle than the observation that airlines portray frequent flying as desirable or that car manufacturers promote automobility centred lifestyles. For instance, Banister et al. (2012, page 468) argue that approaches to reduce greenhouse gas emissions "would have to include ... new unconventional instruments, such as bans on commercial advertising and glamorisation of high $\mathrm{CO}_{2}$ vehicles and certain types of carbon intensive travel [...]". To pursue de-glamorization, for instance through social marketing (Hall, 2014), it would thus be necessary to better understand the workings of mobility and transport glamorization processes, and their relevance in creating network capital.

In light of this, the following sections explore mechanisms of glamorization, discussing objects and aspects glamorized, as well as arenas of glamorization such as social media. We suggest that mobility patterns are now vital and consequential venues of competition for social status, agents of social connectedness, and identity formation. It is such a powerful mechanism because in societies increasingly characterized by insecurity, anxiety, flow and dissolving structures, it is our mobility patterns that paradoxically create the network capital to remain socially connected (Gössling, Cohen and Hibbert, 2015). 


\subsection{Objects and aspects of glamorization}

A discussion of glamorization processes requires a definition of the objects and aspects of hypermobility that appear to be signifiers of network capital. In the past, network capital would mostly have been signified by objects, such as large or powerful cars, private aircraft or yachts, frequent business trips, often to long-haul destinations, or signifiers of frequent flyers, such as often golden or otherwise 'status-coloured' frequent flyer high status cards attached to bags (Thurlow and Jaworski, 2006). While such signifiers persist, contemporary glamorization of (hyper)mobility in some more privileged societies, such as within Northern Europe, appears to be framed around a considerably greater variety of expressions, which only to a limited degree represent objects, rather than issues, aspects or ideas of admiration.

In the following conceptualisation, 13 such aspects are discussed sequentially, but not in order of importance (see Table 1 for a summary list to facilitate navigation). The list is not exhaustive, but appears to represent the first concerted effort in the extant literature to draw together contemporary signifiers of network capital in mobility practices. Many aspects are interrelated, and would often primarily apply to young, western travellers, though powerful mechanisms of globalization of such perspectives across cultures are at work, in particular involving social media (Gössling and Stavrinidi, 2015). As the representations and identities invested in hypermobility and network capital for young, western travellers and the business elite are overlapping, but by no means identical, we also elaborate on how these differences across the upper strata of the hypermobile matter to the glamorization of (hyper)mobility.

\section{Table 1: Aspects of mobility signifying network capital}

\begin{tabular}{|l|l|}
\hline a & Physical distance covered \\
\hline b & Frequency of movement \\
\hline c & Transport mode \\
\hline
\end{tabular}




\begin{tabular}{|l|l|}
\hline d & Cost and comfort of mobility \\
\hline e & Frequent flyer miles collected \\
\hline f & Speed and power of transportation \\
\hline g & Geographical distribution of movement \\
\hline h & Iconic places visited \\
\hline i & Places lived \\
\hline j & Barriers overcome \& off-the-beaten track mobility \\
\hline k & Mobility brand association \\
\hline l & Novelty \\
\hline m & Role model enforcement \\
\hline
\end{tabular}

a) Physical distance covered. Refers to the overall distance one has covered, measured in miles or km, and usually on the basis of the number and length of flights one has made. While physical distance as measured in miles, $\mathrm{km}$ or hours of driving/flight time may not always be the framework for comparison (Riber Larsen and Guiver, 2013), there clearly exist sites that allow for such comparisons. As an example, www.flightmemory.com offers a comparison of individual mobility on the basis of miles/km or hours flown, as well as the number of flights made (see also following aspect: Frequency of movement), or the world map "covered" (see also: Geographical distribution of movement). TripAdvisor (2014), meanwhile, considering itself the world's largest travel site with 150 million reviews, automatically calculates the number of miles/km travelled by its reviewers, as well as the 'percentage of the world travelled' on the basis of the reviewer's home and the places rated.

b) Frequency of movement. Network capital is also characterized by how mobile one is within a given period of time (Urry, 2012), and is expressed in different ways, including through social media. For instance, users of Facebook were found to post travel comments before, during and after trips, apparently in an attempt to communicate 
frequency in movement (Gössling and Stavrinidi, 2015). Another example is frequent flyer status cards displayed in public by business travellers, also representing frequency in movement, in association with social status. Frequent flyers may thus be considered as 'superelites' who consume both aeromobility and its semiotic context (Lash and Urry, 2004), at least in the highly structured social spaces represented by airports (Thurlow and Jaworski, 2006).

c) Transport mode. Different transport modes appear to represent different degrees of network capital, with air travel implying greater capital than car travel, and car travel more than bus or train travel. For instance, the newfound ability to afford a plane ticket, as opposed to relying on long-distance bus, is viewed outwardly in Brazil as proof of upward social mobility (Freire-Medeiros and Name, 2013). While private aircraft may be considered to represent the highest network capital among the business elite, there are distinctions even here with regard to the model of aircraft one can afford.

d) Cost and comfort of mobility. These two aspects may be interrelated or constitute separate aspects. 'Cost' represents the price paid for movement, with for instance first class travel being considerably more expensive than travel in economy class, and related to comfort benefits such as greater legroom in aircraft (Thurlow and Jaworski, 2006). Cost is also a signifier of perceived distance (Riber Larsen and Guiver, 2013), and a significant aspect of car admiration, with for instance topcarrating.com allowing a ranking of cars by price. Even though no research appears to have been conducted regarding these aspects, there appear to exist Veblen effects, wherein conspicuous goods are consumed to signify social status (Bagwell and Bernheim, 1996) even with regard to transport choice; that is, the consumption of specific luxury transport modes because their high cost advertises wealth. 
e) Frequent flyer miles collected. The number of miles collected - including both status and award miles - serve as an expression of mobility and thus network capital. However, frequent flyer miles are also mechanisms rewarding mobility with additional mobility, as well as tangible (additional bags, priority check-in) and intangible (social status, recognition) benefits (Gössling and Nilsson, 2011; Thurlow and Jaworski, 2006). Comparison of frequent flyer miles would be indirect: through the status one has achieved, or in terms of missing miles to reach the next status class. As noted by Gössling and Nilsson (2010), some airlines already have frequent flyer programmes for children as an early socialization into hypermobility.

f) Speed and power of transportation. Speed is a feature of general importance in transport discourses, mostly in the context of aggressive driving. Aggressive, fast driving is glamorized in many movies, with current examples including Fast and Furious (six movies from 2001-2013), Drive Angry (2011), Rush (2013), and Need for Speed (2014), or documentaries including As the Gears Turn (2014). Aggressive driving can be a projection of a superior self-image (Ruvio and Shoham, 2011), while admiration of race pilots (Gössling, 2013) as well as aviators (Adey, 2010) is institutionalized and nationalised. There is for instance considerable glamorization surrounding Formula One auto racing, including transporting the cars and workforce for its Grand Prix events held around the world.

Speed refers both to maximum velocities, as well as the averaged speeds at which one can move (Schafer and Victor, 2000). Averaged speeds are represented in the transport modes one is able to use. Examples include former supersonic aircraft Concorde, or comparisons of car maximum speeds (e.g. topcarrating.com). In a few cases, for leisure 
travellers, slow speeds may also be positively connoted, for instance when representing attractions such as the Trans-Siberian Railways, which however may also be a signifier of distance (see also Physical distance covered; Symbolic places visited). Speed is also associated with power and its distribution, as noted by Cresswell (2010, page 21): “one person's speed is another person's slowness". Many modes of transport are measured, compared or valued on the basis of their power, expressed in Joule, kilowatts, horsepower, or thrust. For instance, websites such as autosnout.com provide lists of cars ranked by horsepower as well as $0-60 \mathrm{mph}$ acceleration times.

g) Geographical distribution of movement. This aspect refers to the number of countries or continents visited. More distant places do not necessarily hold higher social value (Riber Larsen and Guiver, 2013), but a global distribution of destinations visited appears to have considerable importance, particularly for young, western travellers. A wide range of Internet sites as well as social media now offer visualisations of travel. For instance, TripAdvisor provides an overview of the places rated by its members on personalized world maps, as does Facebook for places visited. Such practices contribute to a glorification of the number of places visited, as destinations are 'ticked off' lists and collected as 'trophies' (Burns and Bibbings, 2009; Gössling and Stavrinidi, 2015).

h) Iconic places visited. Some destinations in the world are considered 'iconic', and may represent greater network capital. Even though no research appears to exist that identifies the characteristics of iconic destinations, as notions of 'the iconic' also depend on individual and cultural perceptions, considerable work has been presented on destination image, indicating that some places indeed have greater perceived values than others (e.g. Echtner and Ritchie, 2003; Hanlan and Kelly, 2005). 
i) Places lived. Expressions of hypermobility not only include the number of countries or destinations visited, but as well, and perhaps even more so, the number of and specificity of the countries where one has lived. Positive valuations of dwelling in multiple countries, and learning further languages while doing so, are underpinned by the abstract idealisation of a cosmopolitan sensibility, behind which lurks the privileges of wealth and citizenship of the globe's mobile elite (Skrbis et al, 2004). This is related to the phenomenon of long-haul, long-term independent travel (O'Reilly, 2006), or volunteer-tourism (Wearing, 2001), often during gap years (Lyons et al, 2012; see also Frändberg 2006; 2008). Subsequently, such travel patterns may turn into migration for studies or work (Cohen et al, 2015; Hall, 2005). These movements are captured in social media platforms, with for example Facebook now also offering to depict on a world map the places where one has lived. Pairing places lived with lists of languages spoken signifies not just the power to spend significant time abroad, but also access to educational resources. Network capital, in conclusion, would also be expressed in global patterns of dwelling, and other signifiers such as the number of passports one accumulates (see Ong, 1999 on how some wealthy Chinese migrants are able to thrive through acquiring multiple passports).

j) Barriers overcome \& off-the-beaten-track mobility. Specific locations visited may hold greater network capital than others due to barriers of access, for instance when these are remote, expensive, or restricted in terms of political or legal entry regulation (e.g. de la Barre, 2013). Visits to dangerous destinations (e.g. civil war, unrest, turmoil), or places allowing for dangerous encounters (e.g. shark diving) can be perceived as incurring high social status, particularly by young, western travellers. Social status can also be assigned to motorcycle or train or bicycle travel over great distances or involving difficult tracks. 
k) Mobility brand association. Through brand association, network capital may be built, as various brands have sought to associate specific values with their transport services or products. Examples include, for instance, Mercedes' current 'Into Extremes Fascination of Speed' exhibition (Mercedes, 2014), or Jaguar's 'British Villains - it's good to be bad' (Jaguar, 2014) campaign. Links to mobility can also be subtler, as exemplified by Kidzania theme parks (already existing in 15 countries), where children 'mimic' (Kidzania, 2014) adults, have jobs, and earn and spend money, for instance to rent a car in an Avis rental office. Easyjet's 'Generation Easyjet' campaign frames mobility as an invitation to join a social network, and associates network capital with the mind-set of being young, urban, highly mobile, and open to constantly explore new places (Gössling et al., 2015).

1) Novelty. Novelty refers to specific transport modes that represent advances in technology, such as Airbus' A380 or Boeing's Dreamliner, or space travel (Virginatlantic.com). Being an early-adopter of such innovations, reflected for instance by the raft of celebrities lining up for the first Virgin Galactic space flight, is illustrative of how novel forms of mobility intertwine with markers of prestige.

m) Role model enforcement. Every society has role models who to a considerable degree shape public opinion through their opinions or performances. An example from Germany, the only large industrialized country in the world without a speed limit, may illustrate this. In May 2014, German national soccer league coach Joachim 'Jogi' Löw lost his driving licence for a six-month period after repeated reckless driving incidents (Spiegel, 2014). The mass media (Bild 2014, authors' translation) reported Löw as saying during a related press conference that "I don't think this is anything special. These things happen. I am sure there are some people in this room who also lost their 
driving licenses at some point". Trivialization of illegal or reckless behaviour, either by role models or insinuated by the media, affects public opinion of the social desirability of speeding or aggressive driving, for instance as an expression of 'maleness' (Gössling, 2013).

\subsection{From admiration to glamorization}

From this non-exhaustive review, we conclude that the glamorization of mobility, and in particular hypermobility, now involves a wide range of elements and dimensions, though in virtually all cases with a focus on cars and aircraft. These representations of mobility partially engage what we consider to be 'old' forms of admiration, which are often masculinized, such as depictions of heroic race car drivers and astronauts, successful businessmen, or wider claims invoking social and economic contributions, as exemplified by IATA's (2014) current '100 years of connecting people, cultures, businesses, goods and ideas' campaign. 'Old' forms of glamorization emphasize to a larger degree 'superelites' (Urry, 2007), social contributions made by mobility (e.g. IATA), or technological progress within nationalized contexts (e.g. Jaguar's 2014 campaign). In comparison, we argue that new forms of glamorization are characterized by three key elements: i) they involve far larger populations than previously, in an age of mass mobility; ii) employ different semiotics, i.e. in particular visualisations such as maps; and iii) are characterized by subtle elements of competition, on the basis of opportunities to compare personal corporeal mobilities.

\section{Mass mobility in a globalized world}

Increasingly mobile lifestyles have been discussed out of changing economic, cultural, social and political relations (Coles et al, 2005; Green et al, 1999; Larsen et al, 2007; Lassen, 2006; Shaw and Thomas, 2006). For instance, Frändberg (2008) shows how the mobility patterns of young Swedes change over time, characterized by mobility increasing with age, sequential 
relationships between migration and temporary mobility, and regularity and repetition in longdistance travel patterns, often involving long-distance social relationships. A general conclusion from this line of research is that there are various drivers of individual mobility patterns. Here we argue for a greater recognition of the role of ulterior travel motives underlying these processes: this would specifically include 'liquid' identities, as well as mechanisms of network capital generation in an age of social media dominance (Gössling and Stavrinidi, 2015), and ubiquitous communication of the desirability of mobility: We love flying (in flight screen advertisement June 2014 shown by Thomas Cook). Notably, mobility patterns are aided by a decline in the real cost of travel, witnessed by in particular the rapid growth in low-cost travel (e.g. Nilsson, 2009).

\section{Semiotics}

'Old' forms of glamorization of mobility have involved media such as TV and movies, as well as advertisements launched in magazines, newspapers, radio, visual media, or through the Internet. New forms of glamorization are to a larger degree based on social media and travel sites built on user-generated content, such as TripAdvisor, which offer reference points to one's own travel activity. In particular, Facebook with more than 1 billion users (Facebook, 2014) has become an important platform for the posting of one's own mobility: A study by Gössling and Stavrinidi (2015) concludes that social media fosters corporeal as well as imaginative mobility, with presentations of liquid identities based on texts, pictures (often Selfies), photo albums and 'check-ins', i.e. reference to one's current corporeal position. Representations of mobile identities include landscapes, landmarks, friends and selves. The study also found that photographs shared in 'timelines' put people and selves in focus, while check-ins were visualized in world maps, becoming indicators of a person's 'travelness'. Where children are targeted in campaigns to foster mobile lifestyles, a wide range of different mechanisms may be used, such as Emirates' 2014 campaign to photograph children during the flight, and to supply 
them with the photographs as memories.

\section{Elements of competition}

Finally, new forms of glamorization communicate individual mobility patterns, while involving various elements of competition within peer groups. In Facebook, the competition for mobility would invoke emotions such as feelings of superiority (and vice versa, inferiority), awe and envy, implying the accumulation of network capital for the most mobile (Gössling and Stavrinidi, 2015). For instance, world maps represent spaces of competition of distance consumed, and Facebook discussions revolve around the number of places visited, with encouragement to 'add' certain destinations to one's list of 'places to see', and disappointment where competitions of visiting 'top' destinations are lost. Emotions of admiration or envy among those being less mobile indicate notions of lower social status, reconfirming notions of liquid identities and lifestyles built on mobility. Notably, competition does not always involve direct comparisons with other travellers; it can also be an imaginary comparison with significant others (Hibbert et al, 2013), or constitute a personal reference point, for instance with regard to the number of countries one has visited.

Overall, we conclude that there exist a wide range of aspects related to the measurement of (hyper)mobility, and that there is a growing movement, albeit still framed by power differentials, towards liquid identities built on hypermobile lifestyles, empowered by travel sites and social media on the basis of comparison and resulting competition. Identity, social capital, and network capital are to a greater extent than ever before related to mobility patterns.

\section{The consequences of hypermobility}

While societies appear to rampantly reproduce and develop the processes through which mobility is glamorized, resulting typically in the accrual of network capital for individuals who move fast, frequently and freely, little public attention is given to the negative personal and 
social consequences of hypermobility. Although we recognize that the risks that the hypermobile elite incur are shaped and mitigated based on preferential access to resources such as healthcare, high income and quality housing, and are less consequential than the negative effects of mobility faced for instance, by 'low-skill' labour migrants, we argue the costs of hypermobility on individual lives and societies justifies increased attention, however, for at least two reasons: 1) it is increasingly common; thus its 'darker side', though potentially overshadowed by a cultural glamorization of mobility, may have resonance for more and more people; 2) the social and cultural adherence of hypermobility is a significant barrier to behavioural change in mobility consumption and hence environmental sustainability (Barr \& Prillwitz, 2014; Higham et al, 2013), and greater attention on its negative personal and societal aspects may render counter-evidence that resists discourses that valorize mobility.

Research on frequent business travel has been the primary site of study into the negative consequences of hypermobility. Far less evidence is available in the context of leisure travel, where research has instead tended to focus on tourism's positive implications for its consumers (e.g. Filep and Pearce, 2013). This disparity likely stems from a false 'required/voluntary' dichotomy, whereby it is assumed that one will engage in leisure tourism only when benefits are experienced, thereby rendering the question of a darker personal and social side moot. There are, however, shoots of evidence demonstrating that 'voluntary' hypermobility through leisure travel also has negative sides (e.g. Cohen, 2010). There is recent work examining both the negative and positive implications of business travel (e.g. cosmopolitan identities, broadened understanding of cultural differences, increased open-mindedness, enhanced professional status) (see Gustafson, 2014; Beaverstock et al, 2009). While the benefits of frequent business and leisure travel are well recognized, this paper instead aims to further ventilate their darker sides. 
It is therefore primarily within the context of corporeal travel for business, and where possible drawing upon evidence from leisure travel, that we offer a non-exhaustive characterization of the darker personal and social sides of hypermobility. Our analysis in terms of transport mode largely centres on the ills of frequent aeromobility, despite the car still dominating personal mobility at local and regional scales in more privileged nations (Frändberg and Vilhelmson, 2003). This skew derives from a relative neglect of the car in studies of business and leisure travel, where focus has instead been placed on aeroplanes and international travel. We identify and discuss the negative consequences of hypermobility by organizing them into three key sides, which address costs at both the personal level and that of the broader societal context: 1) physiological consequences; 2) psychological and emotional consequences; and 3) social consequences. This division, however, is for heuristic purposes; we recognise that the sides are not distinct and hence bleed into each other. Our critical review of the negative costs of frequent travel subjectively weaves together a fragmented body of work that crosses the natural and social sciences. We interpretively synthesize others' arguments and empirics, and draw where possible on our own previous empirical work on mobile lifestyles (see reference list), in order to present a first attempt in the literature at a holistic conceptualisation of the darker sides of hypermobility.

\subsection{Physiological consequences}

The potential physiological costs of hypermobility are manifold, with recent scientific evidence adding to an evolving understanding of the various ways in which frequent travel can be harmful. The most commonly discussed physical or biological impact is jet lag, which is a disruption of the body's circadian rhythm (Anderson, 2015). Jet lag affects sleep-wake and gastro-intestinal patterns following high speed travel across many time zones, with significant feelings of jet lag reported even six days after flying (Waterhouse and Edwards, 2004), affecting 
mood, judgement and the ability to concentrate (Striker et al, 2000). Full adaptation of the circadian rhythm following one transmeridian flight can take 11 days (Desir et al, 1981). This interference with the body's rhythms reflects a widespread disruption of many biological processes, including gene expression that influences aging (Archer et al, 2014). Jet lag can even switch off genes that are linked to the immune system, thereby raising the risk of having a heart attack or stroke (Knapton, 2014). Long-term chronic jet lag among airline cabin crew is associated with cognitive deficits including memory impairment (Cho et al, 2000).

For frequent flyers and occasional flyers alike, being in-flight increases the risk of developing deep-vein thrombosis, exposes passengers to more germs, and can contribute to subtle discomforts such as dry eyes and dehydrated skin (Anderson, 2015; Gustafson, 2014). One in ten travellers on long-haul flights develop symptomless deep-vein thrombosis, from which there is the potential to develop fatal blood clots (Scurr et al, 2001). Less publicized, but at the extreme end of a darker side of hypermobility, are arguments that frequent business travellers should be classified as 'radiation workers': flying 85,000 miles a year goes beyond the regulatory limit for public exposure to radiation facilities (i.e. flying New York to Tokyo seven times return, or New York to Seattle return every three weeks in a year), and radiation exposure among commercial aircrew even exceeds that of nuclear power workers (Barish and Dilchert, 2010). With exposure to radiation at high altitude hundreds of times higher than at ground level, the risk of initiating cancer is heightened. The impact is at its greatest on pregnant women, for whom cosmic radiation exposure significantly increases the possibility of leukaemia forming in unborn babies (Barish and Dilchert, 2010).

Whilst the health and safety concerns on arriving at new destinations are wide-ranging (e.g. from diarrhoea to exposure to infectious diseases) (Espino et al, 2002), enough so that some academic journals are devoted solely to travel medicine (i.e. Journal of Travel Medicine and 
Travel Medicine and Infectious Disease), discussion of the impacts of hypermobility on physical health rarely touch upon less acute, cumulative effects of travel behaviour. These include, for instance, most often in the case of frequent business travellers, fewer opportunities for physical exercise, worse eating habits than when at home and sometimes the overconsumption of alcohol (Gustafson, 2014).

Through reward programmes that grant access to lounges and priority boarding, and frequent traveller schemes that expedite security screening for the 'kinetic elite' (Adey, 2006), airlines and airports tease our imaginations with the notion that mobility can be smooth and seamless. Rarely depicted is the accumulated physical tiredness that also goes together with frequent travel. Business travel is often accompanied by early mornings, late evenings and intense working days, and the majority of it, at a global level, is facilitated by flying (Beaverstock et al, 2009). Increasingly, business travellers are forced to take economy class, exacerbating physical and mental fatigue and the overall severity of the physical toll (Beaverstock et al, 2009). This 'creeping tiredness', repeated jet lag and accumulation of travel stress may turn chronic (Black and Jamieson, 2007; Striker et al, 2000), and has been described as 'frequent traveller exhaustion' (Ivancevich et al, 2003). Comparison of the performance impairment of fatigue with that of alcohol intoxication shows that just 17 hours of sustained wakefulness is equivalent to the impairment observed at blood alcohol concentrations above the legal level in many industrialized countries (.05\%): both are frequently related to accidents (Dawson \& Reid, 1997). Of the 1.2 million fatal and 20-50 million non-fatal traffic accidents each year, alcohol and drug abuse are involved in a large share of those accidents, ranging from less than 5\% to more than $50 \%$ in a study of 93 countries (WHO, 2009). How many of these accidents are related to fatigue, high speed, or both, and may be linked to hypermobility, remains unknown.

\subsection{Psychological and emotional consequences}


Jet lag and travel stress not only impact travellers physiologically, but also psychologically and emotionally. Although jet lag is normally reduced to its physical impacts, the geographical and cultural displacement achieved through high-speed long-distance travel can lead to a more holistic sense of 'travel disorientation' (Anderson, 2015). Disorientation can occur before movement even begins, through the stress of anticipating, organizing and preparing for a trip. In the context of business travel, this includes not just leaving the job in good order prior to travel, and making necessary special arrangements with colleagues, but also the implication that time spent travelling will rarely be offset through a reduced workload, and that there may be anxieties associated with work continuing to accumulate (e.g. 'inbox overload') whilst away (Beaverstock et al, 2009; Espino et. al, 2000; Ivancevich et al, 2003). In addition to work, home and family arrangements, pre-trip travel stress includes the potential disorientation of readying oneself to enter a different state of socio-spatial relations at the destination (Anderson, 2015; DeFrank et al, 2000).

Transportation to the destination is a further source of stress and disorientation, as unexpected travel delays due to weather, technical failures and additional security checks at airports contribute to anxiety, frustration and fatigue (Ivancevich et al, 2003). Arriving to acutely felt differences in temperature, humidity, altitude or pollution (Anderson, 2015), as well as different smells, sounds and tastes, while potential sources of enjoyment and excitement, can also contribute to a sense of confusion and uncertainty (Hottola, 2004). The affront on the senses may be overwhelming, even resulting in 'overload shock' (Hottola, 2004). The demand to effectively operate in unfamiliar environments and navigate cultural differences can be an intensive one, particularly when business travel requires meeting rigid schedules (Welch et al, 2007). Anxieties over health, personal safety and security, ranging from the loss of data to terrorism, add a further toll on already stressed travellers (Beaverstock et al, 2009; DeFrank et 
al, 2000).

Hypermobility is frequently an isolating and lonely experience. Although taking a trip often opens new opportunities for making fresh social connections (Bergström, 2010), and renewing past bonds, both Adler and Adler's (1999) study of transient resort workers and Cohen's (2011) work on backpackers who travelled on and off for years, illustrates how new friendships and romantic relationships forged through mobility have a tendency to be situational, expendable and short-lived. Mobile lifestyles left many of the participants in these studies searching for more enduring relationships. Mobility in such cases cuts both ways, leading also to distress when returning 'home', with similarities to returning military service members who have been deployed for long periods of time (Beder, Coe and Sommer, 2011). A lack of co-presence with friends and family can lead to divergent interests and worldviews, encouraging a sense of isolation that in severe cases may even engender depression among returnees (Pocock and McIntosh, 2011). This sense of alienation often pushes young, western travellers back into searching for social cohesion through mobile lifestyles (Cohen, 2011), ironically caging people within the very same corporeal mobilities through which they sought ideals of freedom.

Isolation is also documented amongst business travellers; not just for those who travel, but also those 'left behind' (Gustafson, 2014). Espino et al (2002) report that travelling staff felt both a sense of isolation and guilt at leaving behind their spouse and children, while at the same time spouses felt resentment and anger; frequent trips of long duration led to an emotional distancing between partners.

Hypermobility not only foments emotional and psychological strains in social cohesion, but also in how one relates to place and perceives personal identity (Cohen et al, 2015). Although frequent travellers are well connected to global networks, this is typically at the expense of 
local place-bounded identities (Frändberg and Vilhelmson, 2003). This is not assuming a deterritorialization of place-identity whereby 'home' is found in motion, but rather a weakening of ties at local and community scales. The counter side of this corporeal absence at those scales is increased presence 'away', often in diverse socio-spatial environments. Sustained and repeated exposure to different cultural practices, while associated with the development of cosmopolitan sensibilities and global citizenry (Hannerz, 2002), may also lead to a sense of identity confusion: indeed, Cohen's (2010) work on backpackers who travelled for years on end revealed several who had developed a sense of being metaphorically 'lost'.

In more extreme cases, mobility can engender psychological disorders and mental illness. Studies from consular psychiatry have examined how 'pathological tourism' fosters 'mad [leisure] travellers' who have severely disrupted conceptions of personal identity (Airault, 2000; Hacking, 1998). Liese et al (1997) found in a study of the medical insurance claims of 10,000 World Bank staff a nearly three-fold increase in psychological claims by business travellers $(4,000$ of those staff) as opposed to non-travellers. The findings suggest that hypermobility can contribute to a significantly higher risk of developing psychological disorders.

\subsection{Social consequences}

Many of the above aspects concerning the darker physiological, emotional and psychological sides of hypermobility have already illustrated connections to social consequences. But the costs at kinship, friendship and community levels entail at least several further dimensions. As Bergström (2010) observes, despite advances in communication technologies, increasing travel indicates decreasing time for co-present social life at home and locally. At home, consequences include a negative impact on children's behaviour due to the emotional upset of a parent away 
frequently or for extended periods (Johnson et al, 2013). This reduced ability to participate fully in family life is often exasperated by the limited time in between trips being largely spent recovering from fatigue (Black and Jamieson, 2007). Repeated absence from key family milestones and events, such as birthdays, can lead to a loss of family role (Black and Jamieson, 2007). These effects remain highly gendered, given that jobs requiring frequent travel have been a traditionally male sphere (Bergström Casinowsky, 2013). For instance, 77\% of US citizens on business trips in 2002 were male (Aguilera, 2008). Black and Jamieson (2007) observe that frequent business travel by one parent could prevent the other, who is nearly always female, from entering the labour market because of domestic commitments.

Domestic responsibility in light of hypermobility is gendered in other persisting ways. Among male frequent business travellers, Black and Jamieson (2007) found 'stay at home' wives to be the norm, with women in these cases shouldering the bulk of domestic work as the men held far less household and childcare duties. Frequent female business travellers and mothers, however, applied considerable pressure on themselves, and perceived pressure from their partners and others, to also fulfil the role of mother when away (Black and Jamieson, 2007; see also Bergström Casinowsky, 2013). Thus the allocation of home-based responsibilities when one partner is hypermobile is highly unequal across gender lines.

Reduced time for home-based social life and responsibilities not only affects kinship relations, but also friendships and community. Large amounts of time spent away make it difficult to participate regularly in local cultural activities and organizations, team-sports and in voluntary community work (Høyer and Naess, 2001). Gustafson (2014) found frequent business travellers tended to sacrifice local collective activities and instead prioritize their immediate families when returning from trips. This supports Bergström's (2010, page 382) observation that frequent business travellers develop strategies for economizing on time, "discarding 
relationships with more peripheral acquaintances and focusing on the family and closest friends instead". Whether conscious or not, such tactics reduce the scale and intensity of the traveller's local social network (Bergström, 2010), and thus have the potential to undermine social cohesion in communities where hypermobility is prevalent (Putnam, 2000).

Although a darker dimension of hypermobility is typically a scaling back of one's local and community social networks, these spatially closer contacts may be supplanted by new relationships forged in multiple places, and cultivated through physical visits and communication technologies. As mobility often begets mobility, a further consequence of frequent travel is that it can tip into a migration decision (Cohen, 2011), leading people to migrate intra-nationally or to other countries or continents. An implication of migration is that social relations become further spread out (Larsen et al, 2007), and much additional mobility is often needed through visiting friends and relatives travel to maintain these relations (Janta et al, 2015). The nature of kinship and friendship differs, however, in that the latter lack the institutional framework of the family and are hence more vulnerable to erosion through a lack of face-to-face contact (Hardimon, 1994; Litwak and Szelenyi, 1969). Friendships are thus more susceptible to becoming weakened through mobility decisions, despite virtual interactions. Where families do become spread out, despite the considerable efforts often made by migrants to foster transnational families and intimacies, the costs can be high to maintain these kinship relations, both in terms of time and money (Larsen et al, 2007); there is also a reduction in one's ability to give and receive care at a distance (Janta et al, 2015).

Overall, our critical review of the physiological, psychological, emotional and social consequences of hypermobility has rendered some key insights on the impacts of excessive travel. While there is evidence of the impact of chronic jetlag and frequent radiation exposure on airline cabin crew, the implications of these physiological effects on business and leisure 
travellers has largely been ignored. This is paralleled by a relative neglect of the cumulative effects of hypermobile practices in terms of physical and mental tiredness, wherein the relationship between frequent traveller exhaustion and accidents remains unknown. There is also little knowledge on how hypermobility may intersect with the development of psychological disorders, despite fragmented evidence suggesting a relationship. Furthermore, valuable empirics exist on the unequal negative social consequences of business travel in terms of gender dimensions (e.g. Bergström Casinowsky, 2013), but work in this area has not been extended to frequent leisure travel, nor been sufficiently explored along gender lines with regards to physiological costs.

Finally, our analysis has shown how loneliness and isolation occurs through both frequent business and leisure travel, but has given a wider view beyond hypermobile subjects in illustrating how this loneliness also manifests at 'home', both for returning travellers and those 'left behind'. The implications of hypermobility were shown to not only impact personal identity, but also person-person (at both kinship and friendship levels), person-place and person-community relations. This is highly significant in terms of social cohesion as both frequent leisure and business travellers can experience a reduction in scale and intensity of their local social networks. Through these social processes network capital becomes ever more crucial as a resource for gaining social support.

\section{Conclusions}

By juxtaposing the physiological, psychological, emotional, and social consequences of hypermobility with the mechanisms underpinning its glamorization in societies, we have thrown these two extreme sides of hypermobility into bold relief. We recognise these sides are not binary, and that reported darker elements of hypermobility may be perceived brightly by 
some individuals, vice versa and all shades in between (cf. Anderson and Erskine, 2014 on how some hypermobile travellers experience 'tropophilia', or a love of mobility and change in person-place relations). We have demonstrated, however, that the brighter side of hypermobility is persistently glamorized in contemporary discourse, with the darker sides largely overlooked and ignored, and even made invisible by the social mechanisms through which mobility is linked to network capital.

A wide range of objects and aspects of hypermobility signify network capital. Physical distance covered, the frequency of movement, numbers of places lived in or iconic sites visited, their remoteness and the speed and mode of transport through which such practices take place, are all ways through which network capital is articulated. Through social media, brand association, frequent flyer programmes, early-adoption of mobility technologies, and role model enforcement, with elements of comparison and competition, hypermobility is performed, mobile identities are constituted and frequent travel is adorned by societies. These powerful discourses shape our understanding of mobility, assigning status and network capital to travel, and ascribing anti-status or reduced capital to the less mobile. Even when darker sides of hypermobility are touched upon, they may be framed in ways that glamorize. An example may be jet lag, a phenomenon commonly affecting large numbers of long-distance travellers. When mentioned to explain one's tiredness, 'jet lag' also invokes the semiotics of speed, distance and freedom to travel, becoming a signifier of 'travelness' and a representation of network capital. We postulate that glamorization processes are powerful over and beyond positive framings of mobility in that darker sides of mobility are covered up, or even become instruments in expressing one's travelness.

This paper has attempted to throw light on the darker sides of hypermobility, in a first interdisciplinary attempt in the literature at a holistic conceptualisation of the negative 
consequences of frequent leisure and business travel. Such an understanding is crucial as people increasingly lead lives that are more geographically spread and dependent on network capital (Larsen et al, 2006). Our critical review and original interpretive synthesis is aimed as a corrective to an imbalanced societal discourse that privileges moving fast, frequently and freely. We have demonstrated that the costs of hypermobility can be substantial, with significant consequences for those travelling, their families and their communities. The present paper has identified and drawn together these darker sides of hypermobility, with limited scope here for their quantification. Further research should for example quantify the public health costs associated with hypermobility. This paper has additionally only touched upon gender issues, and the linkages between the darker sides of hypermobility and those of migration; in the latter there is already substantial evidence on the personal and societal consequences of migration (e.g. Grove and Zwi, 2006; Nowok et al, 2013). A full comparative analysis of the consequences of hypermobility and migration is necessary, particularly in terms of health issues. A dedicated analysis of gender dimensions in both the glamorization of hypermobility and in its negative consequences is also warranted, but was outside the scope of the present paper.

Our focus here has been on the broader consequences of hypermobility for individuals and society. With parallels for instance to the unsustainability of post-war suburbanization and urban sprawl in the United States (e.g. Goetz, 2013), cultures of hypermobility likewise impact spatial characteristics. Hypermobility thus also has important implications for defining social space and impacting social and environmental sustainability, with these extending from local to global scales. Hypermobility engenders a rescaling of social interaction: it affects kinship, friendship and local community relationships, contributing to a stretching out of relations (Larsen et al, 2007), which our review reveals is often experienced as a negative consequence. As network capital becomes an increasingly important social resource, it is therefore not only a form of capital from which some are socially excluded, but also a powerful determinant of 
how space and sociality are reconfigured. Crucially, as our review has shown, such reconfigurations also have a darker side.

Our rendering of evidence on the personal costs of hypermobility, and the mechanisms through which network capital is produced, therefore also lends itself as counter-evidence that can be deployed for a normative agenda. We have provided evidence that can be used to resist discourses that make hypermobility fashionable. Only when these discourses are better understood will it become possible to break the intricate bonds between high mobility and social capital, and to ultimately change transport behaviour.

\section{References}

Adey, P 2006, “'Divided We Move’: The Dromologics of Airport Security and Surveillance”, in Surveillance and Security: Technological Politics and Power in Everyday Life, Ed T Monahan (Routledge, New York) pp 195-208

Adey P 2010, "'Ten thousand lads with shining eyes are dreaming and their dreams are wings': Affect, airmindedness and the birth of the aerial subject" Cultural Geographies 18(1) 63-89

Adler P A, Adler P 1999, “Transience and the postmodern self: The geographic mobility of resort workers" The Sociological Quarterly 40(1) 31-58

Airault R 2000, Fous de l'Inde: Delires d' Occidentaux et sentiment oceanique [Crazy about India: Western frenzies and oceanic feeling] (Payot, Paris)

Aguilera A 2008, "Business travel and mobile workers" Transportation Research Part A 42 , 
$1109-1116$

Anderson J 2015, "Exploring the consequences of mobility: Reclaiming jet lag as the state of travel disorientation" Mobilities, 10(1), 1-16

Anderson J, Erskine, K 2014, "Tropophilia: A study of people, place and lifestyle travel" Mobilities, 9(1), 130-145

Archer S, Laing E E, Möller-Levet C S, van der Veen D R, Bucca G.....Dijk D-J 2014, "Mistimed sleep disrupts circadian regulation of the human transcriptome" Proceedings of the National Academy of Sciences DOI:10.1073/pnas.1316335111

Bagwell LS, Bernheim BD 1996, "Veblen effects in a theory of conspicuous consumption" The American Economic Review 86(3) 349-373

Banister D, Schwanen T, Anable J 2012, "Introduction to the special section on theoretical perspectives on climate change mitigation in transport" Journal of Transport Geography $\mathbf{2 4}$ $467-470$

Barish R J, Dilchert S 2010, "Human resource responsibilities: Frequent flyer radiation exposure" Employee Responsibilities and Rights Journal 22 361-369

Barr S, Prillwitz J 2014, “A smarter choice? Exploring the behaviour change agenda for environmentally sustainable mobility" Environmental and Planning C: Government and Policy 32(1) 1-29 
Barry K M 2007, Feminity in Flight: A History of Flight Attendants (Duke University Press, NC)

Baum T 2012, "Working the skies: Changing representations of gendered work in the airline industry, 1930-2011” Tourism Management 33(5) 1185-1194

Bauman Z 2007, Liquid Modernity (Blackwell Publishers Ltd, Oxford)

Beaverstock J V, Derudder B, Faulconbridge J R, Witlox F 2009, “International business travel: Some explorations" Geografiska Annaler: Series B, Human Geography

91(3) 193-202

Beder J, Coe R, Sommer D 2011, "Women and men who have served in Afghanistan/Iraq: Coming home" Social Work in Health Care 50(7) 515-526

Bergström G 2010, “Consequences of overnight work travel for personal social relations: Problems, promises, and further repercussions Mobilities 5(3) 369-386

Bergström Casinowsky G 2013 "Working life on the move, domestic life at standstill? Workrelated travel and responsibility for home and family" Gender, Work and Organization 20(3) $311-326$

Bild 2014, "Oliver Bierhoff scherzt ueber Jogi Löw”, 30 May, http://www.bild.de/sport/fussball/oliver-bierhoff/scherzt-ueber-loews-lappen-verlust36156952.bild.html 
Black I, Jamieson S 2007, “Up, up and fading away: The work and family life of executive international travellers" Policy and Practice in Health and Safety 5(2) 63-78

Burns P, Bibbings L 2009, "The end of tourism? Climate change and societal challenges" $21^{s t}$ Century Society 4(1) 31-51

Carrasco, JA, Cid-Aguayo, B 2012, "Network capital, social networks, and travel: An empirical illustration from Concepción, Chile” Environment and Planning A 44 1066-1084

Cho K, Ennaceur A, Cole J C, Chang K S 2000, "Chronic jet lag produces cognitive deficits" The Journal of Neuroscience 20(R66) 1-5

Cohen S A 2010, "Personal identity (de)formation among lifestyle travellers: A double-edged sword" Leisure Studies 29(3) 289-301

Cohen S A 2011, "Lifestyle travellers: Backpacking as a way of life" Annals of Tourism Research 38(4) 1535-1555

Cohen S A, Duncan T, Thulemark M 2015, "Lifestyle mobilities: The crossroads of travel, leisure and migration" Mobilities 10(1) 155-172

Coles T, Duval D T, Hall CM 2005, “Tourism, mobility, and global communities: New approaches to theorising tourism and tourist spaces", in Global Tourism, Third Edition Ed W F Theobald (Elsevier, Amsterdam) pp 463-481

Cresswell T 2010, “Towards a politics of mobility” Environment and Planning D: Society 
and Space 28 17-31

Dawson D, Reid K 1997, "Fatigue, alcohol and performance impairment” Nature 388(July) 235

DeFrank R S, Konopaske R, Ivancevich J M 2000, “Executive travel stress: Perils of the road warrior" Academy of Management Executive 14(2) 58-71

De la Barre S 2013, “Wilderness and cultural tour guides, place identity and sustainable tourism in remote areas" Journal of Sustainable Tourism 21(6) 825-844

Desir D, Van Cauter E, Fang V S, Martino E, Jadot C, Spire J-P....Goldstein J 1981, "Effect of jet lag on hormonal patterns. I. Procedures, variations in total plasma-proteins, and disruption of adrenocorticotropin-cortisol periodicity" Journal of Clinical Endocrinology and Metabolism 52 628-641

Dixon-Woods M, Bonas S, Booth A, Jones DR, Miller T, Sutton AJ, Shaw RL, Smith JA, Young B 2006a "How can systematic reviews incorporate qualitative research? A critical perspective" Qualitative Research 6(1) 27-44

Dixon-Woods M, Cavers D, Agarwal S, Annandale E, Arthur A, Harvey J, Hsu R, Katbama S, Olsen R, Smith L, Riley R, Sutton AJ 2006b "Conducting a critical interpretive synthesis of the literature on access to healthcare by vulnerable groups" BMC Medical Research Methodology 6(35) 1-13

Echtner C, Ritchie J R B 2003, “The meaning and measurement of destination image The 
Journal of Tourism Studies 14(1) 37-48

Edensor T 2004, “Automobility and national identity: Representation, geography and driving practice" Theory, Culture and Society 21(4-5) 101-120

Espino C M, Sundstrom S M, Frick H L, Jacobs M, Peters M 2002, “International business travel: Impact on families and travellers" Occupational and Environmental Medicine 59 309322

Facebook 2014, “About Facebook”, 22 May, https://www.facebook.com/facebook/info

Filep, S, Pearce, P 2013, Tourist Experience and Fulfilment: Insights from Positive Psychology (Routledge: London)

Frändberg L 2006, “International mobility biographies. A means to capture institutionalisation of long-distance travel?" Current Issues in Tourism 9(4\&5) 320-334

Frändberg L 2008, "Paths in transnational time-space: Representing mobility biographies of young Swedes" Geografiska Annaler: Series B 90(1) 17-28

Frändberg L, Vilhelmson B 2003, “Personal mobility: A corporeal dimension of transnationalisation. The case of long-distance travel from Sweden" Environment and Planning A 35 1751-1768

Freire-Medeiros B, Name L 2013, "Flying for the very first time: Mobilities, social class and environmental concerns in a Rio de Janeiro favela" Mobilities 8(2) 167-184 
Goetz A 2013, “Suburban sprawl or urban centres: Tensions and contradictions of smart growth approaches in Denver, Colorado" Urban Studies 50(11) 2178-2195

Gössling S 2013, “Advancing a clinical transport psychology” Transportation Research Part F: Traffic Psychology and Behaviour 19 11-21

Gössling S, Ceron J-P, Dubois G, Hall C M 2009) “Hypermobile travellers”, in Climate Change and Aviation Eds S Gössling, P Upham (Earthscan, London) pp 131-149

Gössling S, Cohen S A 2014, "Why sustainable transport policies will fail:

European Union climate policy in the light of transport taboos" Journal of Transport Geography 39 197-207

Gössling S, Cohen S A, Hibbert J 2015, “Tourism as connectedness" Annals of Tourism Research (submitted)

Gössling S, Nilsson J H 2010, "Frequent flyer programmes and the reproduction of mobility" Environment and Planning A $\mathbf{4 2}$ 241-252

Gössling S, Stavrinidi I 2015, "Facebook and mobility. The emergence of liquid identities" Mobilities (submitted)

Green A E, Hogarth T, Shackleton R E 1999, "Longer distance commuting as a substitute for migration in Britain” International Journal of Population Geography 5 49-68

Grube J 2005, "Preventing alcohol-related problems: Public policy strategies”, Transportation 
Research Circular: Implementing Impaired Driving Countermeasures, 21-23 August 2003, http://onlinepubs.trb.org/onlinepubs/circulars/ec072.pdf

Grove N J, Zwi A B 2006, "Our health and theirs: Forced migration, othering and public health" Social Science \& Medicine 62(8) 1931-1942

Gustafson P 2014, “Business travel from the traveller's perspective: Stress, stimulation and normalization" Mobilities 9(1) 63-83

Hacking I 1998, Mad Travellers: Reflections on the Reality of Transient Mental Illnesses (Free Association Books, London)

Hall C M 2005, Tourism: Rethinking the Social Science of Mobility (Pearson Education Limited, London)

Hanlan J, Kelly S 2005, "Image formation, information sources and an iconic Australian tourist destination" Journal of Vacation Marketing 11(2) 163-177

Hannerz U 2002, "Where we are and who we want to be", in The Postnational Self: Belonging and Identity Eds U Hedetoft, M Hjort (University of Minnesota Press, Minneapolis) pp 217-232

Hardiman M O 1994, "Role obligations” The Journal of Philosophy 91(7) 333-363

Hibbert J F, Dickinson J E, Gössling S, Curtin, S 2013, “Identity and tourism mobility: An exploration of the attitude-behaviour gap" Journal of Sustainable Tourism 21(7) 999-1016 
Higham J, Cohen S A, Peeters P, Gössling S 2013, "Psychological and behavioural approaches to understanding and governing sustainable mobility" Journal of Sustainable Tourism 21(7) 949-967

Hottola P 2004 “Culture confusion: Intercultural adaptation in tourism” Annals of Tourism Research 31(2) 447-466

Høyer K, Naess P 2001, “Conference tourism: A problem for the environment, as well as for research?" Journal of Sustainable Tourism 9(6) 451-470

IATA, International Air Transport Association 2014, "Join us in celebrating 100 years of connecting people, cultures, businesses, goods and ideas. Small world, big future, 21 May, http://www.iata.org/Pages/default.aspx

Ivancevich J M, Konopaske R, DeFrank R S 2003 “Business travel stress: A model, propositions and managerial implications" Work \& Stress: An International Journal of Work, Health \& Organisations 17(2) 138-157

Jaguar 2014, "It's good to be bad. A new British villain is in town. And it simply commands respect”, 21 May, http://www.jaguar.co.uk/good-to-be-bad/index.html Accessed 21 May 2014

Janta H, Cohen S A, Williams A 2015, "Rethinking visiting friends and relatives mobilities" Population, Space and Place, DOI: 10.1002/psp.1914

Johnson S, Li J, Kendall, G, Strazdins L, Jacoby P 2013, “Mothers' and fathers‘ work hours, 
child gender, and behavior in middle childhood" Journal of Marriage and Family 75 56-74

Kidzania 2014, “The Concept”, 20 May, http://www.kidzania.com/the-concept.php

Knapton S 2014 "Why night shift and jet lag make you feel so bad" The Telegraph 21

January, http://www.telegraph.co.uk/science/science-news/10584723/Why-night-shift-and-

jet-lag-make-you-feel-so-bad.html

Larsen, J, Axhausen, KW, Urry, J 2006, “Geographies of social networks: Meetings, travel and communications" Mobilities 1(2) 261-283

Larsen J, Urry J, Axhausen K W 2007, "Networks and tourism. Mobile social life” Annals of Tourism Research 34(1) 244-262

Lash S, Urry J 2004, Economies of Signs and Spaces (Sage, London)

Lassen C 2006 “Aeromobility and work” Environment and Planning A 38 301-12

Liese B, Mundt K, Dell L, Nagy L, Demure B 1997 “Medical insurance claims associated with international business travel" Occupational and Environmental Medicine 54 499-503

Litwak E, Szelenyi I 1969 "Primary group structures and their functions: Kin, neighbors, and friends" American Sociological Review 34(4) 465-481

Lyons K, Hanley J, Wearing S, Neil J 2012, “Gap year volunteer tourism. Myths of global citizenship? Annals of Tourism Research 39(1) 361-378 
Mercedes 2014, “Mercedes-Benz Ausstellung: Into Extremes - Faszination Geschwindigkeit im Europa-Park" 20 May, http://media.daimler.com/dcmedia/0-921-1086062-49-1689565-1$\underline{0-0-0-0-00-0-0-1-0-0-0-0-0 . h t m l}$

Nilsson M, Küller R 2000, “Travel behaviour and environmental concern” Transportation Research Part D 5 211-234

Nilsson J H 2009, “Low-cost aviation” in Climate Change and Aviation Eds S Gössling, P Upham (Earthscan, London) pp 113-129

Nowok B, Ham M V, Findlay A M, Gayle V 2013, "Does migration make you happy? A longitudinal study on internal migration and subjective well-being" Environment and Planning A 45(4) 986-1002

Ong A 1999, Flexible Citizenship: The Cultural Logics of Transnationality (Duke University Press: Durham)

O’Reilly C C 2006, "From drifter to gap year tourist: Mainstreaming backpacker travel" Annals of Tourism Research 33(4) 998-1017

Pocock N J, McIntosh A J 2011, “The return from travel: A new beginning?” Current Issues in Tourism 14(7) 631-649

Putnam R 2000, Bowling Alone: The Collapse and Revival of American Community (Simon \& Schuster, New York) 
Rettie, R 2008 “Mobile phones as network capital: Facilitating connections” Moblities 3(2) 291-311

Riber Larsen G, Guiver J 2013, “Understanding tourists' perceptions of distance: A key to reducing the environmental impacts of tourism mobility” Journal of Sustainable Tourism 21(7) 968-981

Ruvio A A, Shoham A, 2011, “Aggressive driving: A consumption experience” Psychology and Marketing 28(11) 1089-1114

Schafer A, Victor D G 2000, “The future mobility of the world population" Transportation Research Part A 34 171-205

Schwanen T, Banister D, Anable J 2012, "Rethinking habits and their role in behaviour change: The case of low-carbon mobility" Journal of Transport Geography 24 522-532

Scurr J H, Machin S J, Bailey-King S, Mackie I J, McDonald S, Smith P D C 2001, "Frequency and prevention of symptomless deep-vein thrombosis in long-haul flights: A randomised trial” The Lancet 357 1485-1489

Shaw S, Thomas C 2006, Social and cultural dimensions of air travel demand: Hyper-mobility in the UK?" Journal of Sustainable Tourism 14(2) 209-215

Sheller M 2004, “Automotive emotions: Feeling the car" Theory, Culture and Society 21(4/5) $221-245$ 
Sheller M, Urry J 2006, “The new mobilities paradigm” Environment and Planning A 38(2) $207-226$

Skrbis Z, Kendall G, Woodward I 2004, “Locating cosmopolitanism: Between humanist ideal and grounded social category" Theory, Culture \& Society 21(6) 115-136

Spiegel 2014, "Löw ohne Fuehrerschein: Mit 18 Punkten abgestiegen” 30 May,

http://www.spiegel.de/sport/fussball/loew-ohne-fuehrerschein-bundestrainer-ist-ein-vorbild-a972008.html

Striker J, Dimberg L, Liese, B H 2000, “Stress and business travel: Individual, managerial and corporate concerns" Journal of Organizational Excellence Winter 3-9

Thurlow C, Jaworski A, 2006, “The alchemy of the upwardly mobile: Symbolic capital and the stylization of elites in frequent-flyer programmes" Discourse and Society 17 99-135.

Urry J 2007, Mobilities (Polity Press, Cambridge)

Urry J 2012, “Social networks, mobile lives and social inequalities” Journal of Transport Geography 21, 24-30

Waterhouse J, Reilly T, Edwards B 2004, “The stress of travel” Journal of Sport Sciences 22 946-966.

Wearing S 2001, Volunteer Tourism. Experiences that Make a Difference (CABI Publishing, 
Wallingford, UK)

Welch D E, Welch L S, Worm V 2007, “The international business traveller: A neglected but strategic human resource" International Journal of Human Resource Management 18(2) 173183

Wellman B, Frank K 2001 "Network capital in a multi-level world: Getting support from personal communities“, in Social Capital: Theory and Research: Eds N Lin, R.S Burt, K Cook (Chicago: Aldine De Gruyter) pp 233-273

WHO, World Health Organization 2009, "Global status report on road safety” 24 July 2014, http://whqlibdoc.who.int/publications/2009/9789241563840_eng.pdf 